\title{
The c-Met receptor tyrosine kinase inhibitor MP470 radiosensitizes
} glioblastoma cells

\author{
James W Welsh*1, Daruka Mahadevan², Ron Ellsworth², Laurence Cooke3, \\ David Bearss ${ }^{4}$ and Baldassarre Stea ${ }^{5}$
}

\author{
Address: ${ }^{1}$ Departmentr of Radiation Oncology, The University of Texas M. D. Anderson Cancer Center, 1515 Holcombe Blvd., Houston, TX; USA, \\ 2Department of Medicine, University of Arizona Cancer Center, 1515 North Campbell Avenue, Tucson, AZ 85724-5024, USA, ${ }^{3}$ University of \\ Arizona College of Medicine, 1501 North Campbell Avenue, Tucson, AZ 85724-5024, USA, ${ }^{4}$ SuperGen Inc, 4140 Dublin Boulevard, Dublin, CA \\ 94568-7757, USA and ${ }^{5}$ Department of Radiation Oncology, University of Arizona Cancer Center, 1515 North Campbell Avenue, Tucson, AZ \\ 85724-5024, USA \\ Email: James W Welsh* - jwelsh@mdanderson.org; Daruka Mahadevan - DMahadevan@azcc.arizona.edu; \\ Ron Ellsworth - rellswo@email.arizona.edu; Laurence Cooke - lcooke@azcc.arizona.edu; David Bearss - david.bearss@supergen.com; \\ Baldassarre Stea - bstea@azcc.arizona.edu \\ * Corresponding author
}

Published: 22 December 2009

Radiation Oncology 2009, 4:69 doi:10.1186/1748-717X-4-69

This article is available from: http://www.ro-journal.com/content/4/I/69

(C) 2009 Welsh et al; licensee BioMed Central Ltd.

This is an Open Access article distributed under the terms of the Creative Commons Attribution License (http://creativecommons.org/licenses/by/2.0), which permits unrestricted use, distribution, and reproduction in any medium, provided the original work is properly cited.
Received: 27 August 2009
Accepted: 22 December 2009

\begin{abstract}
Purpose: Glioblastoma multiforme (GBM) is resistant to current cytotoxic therapies, in part because of enhanced DNA repair. Activation of the receptor tyrosine kinase c-Met has been shown to protect cancer cells from DNA damage. We hypothesized that inhibiting c-Met would decrease this protection and thus sensitize resistant tumor cells to the effects of radiation therapy.

Materials and methods: Eight human GBM cell lines were screened for radiosensitivity to the small-molecule c-Met inhibitor MP470 with colony-count assays. Double-strand (ds) DNA breaks was quantified by using antibodies to gamma $\mathrm{H} 2 \mathrm{AX}$. Western blotting demonstrate expression of RAD5I, glycogen synthase kinase (GSK)-3 $\beta$, and other proteins. A murine xenograft tumor flank model was used for in vivo radiosensitization studies.

Results: MP470 reduced c-Met phosphorylation and enhanced radiation-induced cell kill by 0.4 logs in SF767 cells. Cells pretreated with MP470 had more ds DNA damage than cells treated with radiation alone. Mechanistically, MP470 was shown to inhibit dsDNA break repair and increase apoptosis. MP470 influences various survival and DNA repair related proteins such as PAKT, RAD5I and GSK3 $\beta$. In vivo, the addition of MP470 to radiation resulted in a tumor-growth-delay enhancement ratio of 2.9 over radiation alone and extended survival time.
\end{abstract}

Conclusions: GBM is a disease site where radiation is often used to address both macroscopic and microscopic disease. Despite attempts at dose escalation outcomes remain poor. MP470, a potent small-molecule tyrosine kinase inhibitor of c-Met, radiosensitized several GBM cell lines both in vitro and in vivo, and may help to improve outcomes for patients with GBM. 


\section{Introduction}

The management of malignant gliomas continues to pose a difficult therapeutic challenge. Use of radiation therapy and chemotherapy after maximal tumor debulking can improve both local control and survival for some patients with malignant gliomas [1]. Unfortunately, despite adjuvant therapy nearly all patients with glioblastoma multiforme (GBM) will eventually develop tumor recurrence and die of the disease. Patterns-of-failure studies conducted after primary therapy for GBM have shown that $75 \%-90 \%$ of patients experience tumor recurrence within $2 \mathrm{~cm}$ of the resection margin [2]. Attempts to increase the local radiation dose have not led to any meaningful improvement in survival when tested in randomized trials [3]. The most likely cause of recurrence is believed to be intrinsic radioresistance, mediated in part by efficient DNA repair. This suggests that interventions aimed at modifying cellular resistance to radiation or chemotherapy may confer a survival benefit.

Hepatocyte growth factor (HGF) is a multifunctional heterodimeric protein typically produced by mesenchymal cells. Its pleiotropic activities are mediated through its cellular receptor, a transmembrane tyrosine kinase encoded by the proto-oncogene c-Met. In malignant cells, HGF has been shown to protect cells from death induced by a variety of DNA-damaging agents, including radiation and topoisomerase inhibitors [4]. Interestingly HGF/SF not only blocked DNA damage-induced apoptosis but also enhanced the rate of repair of DNA strand breaks [5]. HGF also functions as an autocrine or paracrine growth factor and activates a program of cell dissociation and motility coupled with increased protease production that has been shown to promote cellular invasion [6,7]. HGF and c-Met are co-expressed and often overexpressed in a broad spectrum of human solid tumors including lung, breast, and brain malignancies $[7,8]$. Therefore, the overexpression of c-Met by GBM cells suggests that blocking HGF or its receptor c-Met might be an attractive strategy when combined with conventional treatment for the treatment of GBM. A recent review of this approach indicates that several novel inhibitors of the tyrosine kinase activity of cMet have been developed and tested as a single agent or in combination with cytoxic chemotherapy [9]. Although it has previously been shown that targeting HGF or c-Met expression using ribozyme radiosensitizers in GBM cells in vitro and xenograft tumor in vivo [10], demonstration of clinically useful inhibitors of the tyrosine kinase activity of c-Met combined with radiation have not been previously tested in GBM models.

In the work presented here, a novel inhibitor of c-Met tyrosine kinase, MP470 [11], was tested for its ability to radiosensitize GBM cells both in vitro and in vivo.

\section{Materials and methods Cell culture}

All of the human GBM cell lines tested (SF763, SF268, SF295, SF126, SF188, SF767, U-87, and SF210) were obtained from the University of California, San Francisco, and maintained in Dulbecco's Modified Eagle Medium supplemented with $10 \%$ fetal calf serum and $1 \%$ penicillin-streptomycin [12]. Cells were incubated at $37^{\circ} \mathrm{C}$ in a $5 \% \mathrm{CO}_{2}$ incubator. MP470 (SuperGen, Dublin, CA) was stored in the dark at $4^{\circ} \mathrm{C}$ until use, when it was dissolved in dimethyl sulfoxide and used at a final concentration of 5.0-10 $\mu \mathrm{M}$. The drug was added to cells 1 hour before irradiation unless otherwise specified. Control cells were treated with equal volumes of dimethylsulfoxide. A cobalt-60 teletherapy unit (Atomic Energy of Canada Limited Theratron-80) was used to irradiate the GBM cells at a dose rate of $2 \mathrm{~Gy} / \mathrm{min}$.

\section{Cell proliferation assay}

The cytotoxicity of MP470 was assessed in vitro in all eight cell lines by using an MTS assay performed in a 96-well plate format. Cells were plated with a multichannel pipetter and MP470 (to a final concentration of $5 \mu \mathrm{M}$ ) was added to triplicate wells 24-48 hours later, after which the plates were incubated for up to 4 days. The MTS assay was done with a CellTiter $96 \mathrm{AQ}_{\text {ueous }}$ Non-Radioactive Cell Proliferation Assay kit as per the manufactures recommendations (Cat \#G5421, Promega, Madison, WI). The $\mathrm{IC}_{50}$ (the concentration that inhibited proliferation in $50 \%$ of the samples) was determined from standard curves.

\section{In vitro clonogenic assay}

The eight human GBM cell lines were cultured as described above, harvested, counted, and seeded onto 60mm petri dishes at specific cell densities. MP470 (5 $\mu \mathrm{M})$ was added 1 hour before the cells were irradiated with single doses ranging from 2 to $8 \mathrm{~Gy}$, after which the cells were returned to a $37^{\circ} \mathrm{C}$ incubator and cultured for 14 days in the presence of the MP470 before fixation. Cells were fixed for 5 minutes with 3:1 methanol: acetic acid solution and stained for 5 minutes with $0.5 \%$ crystal violet (Sigma, St. Louis, MO) in methanol. Colonies were counted with a Colcount automated colony counter (Optronix, Milton Port, Oxford, UK) using the discrete colony mode. The surviving fraction was calculated as (mean colony counts $) /$ (cells plated $) \times($ plating efficiency), where plating efficiency was defined as (mean colony counts)/(cells plated for unirradiated controls). All experiments were done in duplicate in 3 independent experiments and averaged data points represent the means \pm standard deviations (SD). 


\section{Apoptosis assay}

Near-confluent SF767 cells were pretreated with $5 \mu \mathrm{M}$ MP470 irradiated ( $8 \mathrm{~Gy}$ ), and analyzed 4 hours later as follows. Briefly, after pretreatment with MP470 for 5 hours, cells were suspended in phosphate-buffered saline (PBS, made by dissolving $8 \mathrm{~g} \mathrm{NaCl}, 0.2 \mathrm{~g} \mathrm{KCl}, 1.44 \mathrm{~g}$ $\mathrm{Na}_{2} \mathrm{HPO}_{4}$, and $0.24 \mathrm{~g} \mathrm{KH}_{2} \mathrm{PO}_{4}$ in $800 \mathrm{~mL}$ of $\left.\mathrm{H}_{2} \mathrm{O}\right)(\mathrm{pH}$ $7.2)$ containing acridine orange $\left(1 \mu \mathrm{g} \cdot \mathrm{mL}^{-1}\right)$ and RNAse A and then co-stained with $1 \mu \mathrm{g} \cdot \mathrm{mL}^{-1}$ ethidium bromide (all reagents from Sigma); cells were then washed and examined under a fluorescence microscope $(\times 150$, Olympus, Center Valley, PA; exciting filter BG12, barrier filter 05.30). For quantitative analyses, 200 cells were counted and the percentages of necrotic and apoptotic cells calculated.

\section{$\gamma-H 2 A X$ assay}

Double-stranded (ds) DNA breaks lead to the formation of $\gamma$-H2AX, a unique histone complex. We used a $\gamma$-H2AX antibody (Upstate Cat \#05-636, Millipore, Billerica, MA) to visualize dsDNA breaks as follows. Cells were plated in chamber slides, grown for 48 hours, and treated with 5 $\mu \mathrm{M} \mathrm{MP} 470$, one hour later, the cells were irradiated with 4 Gy and processed either 1 hour or 8 hours later. Cells were first fixed in 4\% paraformaldehyde and incubated with the primary antibody against $\gamma$-H2AX. The primary antibody was then washed off, and a secondary antibody conjugated to fluorescein isothiocyanate (FITC) was added to the slides. DNA damage was visualized by using confocal microscopy. Median intensity of each cell was calculated using Photoshop and a 2 sided t-test was used to calculate the difference.

\section{Comet assay}

dsDNA breaks were visualized by using a neutral comet assay (Cat \#4250-050-K, Trevigen, Gaithersburg, MD). Cells were plated on 10-cm BD Falcon Cell Culture Plates (BD, Franklin Lakes, NJ), incubated for 2 days, treated with $10 \mu \mathrm{M}$ MP470 or dimethylsulfoxide (control) for 1 hour, and then irradiated with $8 \mathrm{~Gy}$. Cells were then trypsinized, placed on glass slides, and subjected to electrophoresis according to the manufacturer's instructions. dsDNA breaks were measured by olive tail movement, (OTM), defined as (tail length) $\times$ (the fraction of total DNA in the tail)[13]. OTM values were calculated with TriTek Comet Score V 1.5 software (The TriTek Corporation, Sumerduck, VA). Data points represent means \pm SDs from triplicate experiments.

\section{Western blotting}

Cells were plated on 10-cm petri dishes and grown for 2448 hours. MP470 was then added at a concentration of 10 $\mu \mathrm{M}$ (in $100 \%$ dimethlysulfoxide) for maximum inhibition. Cells were incubated with the MP470 for 24 hours (unless otherwise specified) before being irradiated with 4
Gy. After irradiation, cells were lysed on the plates by adding $350 \mu \mathrm{L}$ of sodium dodecyl sulfate lysis buffer $(20 \mathrm{mM}$ HEPES [pH 7.9], $400 \mathrm{mM} \mathrm{NaCl}, 1 \mathrm{mM}$ EDTA, $1 \mathrm{mM}$ EGTA, 1\% NP40, $1 \mathrm{mM}$ DTT, $1 \mathrm{mM}$ phenylmethylsulfonyl fluoride, $1 \mathrm{mg} / \mathrm{mL}$ aprotinin, $1 \mathrm{mg} / \mathrm{mL}$ leupeptin, 250 $\mathrm{mg} / \mathrm{mL}$ benzamide, $50 \mathrm{mM} \mathrm{NaF}$, and $1 \mathrm{mM} \mathrm{NaO}_{3} \mathrm{~V}_{4}$ ). The lysate was transferred to a $1.5-\mathrm{mL}$ microcentrifuge tube, boiled for 5 minutes with intermittent vortexing, and then centrifuged for 5 minutes at 10,000 rpm, after which the supernatant was transferred to a new microcentrifuge tube. Lysates were subjected to electrophoresis on $10 \%$ 20\% HCl pre-poured gels (Cat \#161-1108, Bio-Rad, Hercules, CA). The proteins were then transferred to nitrocellulose paper and probed with the appropriate antibodies under the conditions recommended by the suppliers. The following antibodies were used Phospho-AKT (Ser 473 Cat, \#4058), glycogen synthase kinase (GSK)-3 $\beta$ with Phospho-GSK-3 $\beta$ (Ser9, \#9336) Cell Signaling Technology, Danvers, MA), RAD51 H-92 (Santa Cruz Biotechnology, Santa Cruz, CA) and c-Met phosphospecific Anti-cMet [pY1003] (Cell Signaling Technology) [14].

\section{siRNA experiments}

siRNA to c-Met (sc-29397) and control siRNA (sc-37007) were purchased from Santa Cruz Biotechnology. The transfection reagent Lipofectamine was from Invitrogen (Carlsbad, CA). U87 cells were grown to 70\% confluence and transfected with siRNA at a final concentration of 100 nM. Seventy-two hours later, the cells were lysed for western blotting analysis as described above.

\section{Animal experiments}

To create subcutaneous tumors, cells $(4 \times 106$ per animal $)$ were implanted in the flanks of 32 outbred athymic nude mice, 8 per arm (Taconic, Germantown, NY). U87 cells were chosen for their high level of c-Met expression and ability to rapidly produce tumors. Twenty-five days after the cells were injected, animals were pair-matched (based on tumor volume) and assigned to one of four treatment groups: control; MP470 (60 $\mathrm{mg} / \mathrm{kg})$ alone; radiation alone ( 2 Gy per day $\times 10$ days); and MP470 + radiation. MP470 was delivered daily by gavage at a dose of $60 \mathrm{mg} /$ $\mathrm{kg}$ in peanut oil starting on day 25 for 14 consecutive days. Radiation was started on day 27 and consisted of 2 Gy per day delivered to the tumor by a cobalt-60 irradiator (Theratron-80).

Radiation was delivered daily, 5 days per week for 2 weeks, at 1 hour after the MP470 treatment. The total cumulative dose delivered to the tumor was thus $20 \mathrm{~Gy}$. Animals were euthanized by $\mathrm{CO}_{2}$ asphyxiation when the tumor volume reached $2000 \mathrm{~mm}^{3}$, as required by our institutional animal care and use committee protocol \#07-029. All remaining animals were euthanized on day 48. Tumors were measured with calipers every 5 days and 
the volume calculated according to the formula $\left(a^{2}-b / 2\right)$, where $\mathrm{a}$ is the smallest diameter and $\mathrm{b}$ is the largest diameter of the tumor.

Tumor growth delay was expressed in absolute and normalized terms as follows. Absolute growth delay (AGD) was defined as the number of days for tumors in the radiation-only and the MP470 + radiation groups to reach $1,500 \mathrm{~mm}^{3}$ minus the number of days for tumors in the control group to reach the same size. Normalized growth delay (NGD) was calculated as the number of days for tumors in the combined-therapy group to reach 1,500 $\mathrm{mm}^{3}$ minus the number of days for tumors in the MP470only group to reach $1,500 \mathrm{~mm}^{3}$. The enhancement factor was then determined by dividing the NGD for the group receiving MP470 plus radiation by the AGD for the group given radiation alone. All statistical analyses were carried out with Stata 9.2 for Windows (College Station, TX), and $P$ values $<0.05$ were considered significant.

\section{Results \\ Cytotoxicity and radiosensitization}

The small-molecule tyrosine kinase inhibitor MP470 was designed to target c-Met, although it also inhibits the c-Kit receptor and platelet-derived growth factor receptor at nanomolar levels [11]. To evaluate its effect on proliferation eight GBM cell lines were used in an MTS assay. All eight cell lines proved to be sensitive to MP470 alone, with $\mathrm{IC}_{50}$ values ranging from $1 \mu \mathrm{M}$ to $10 \mu \mathrm{M}$ (median 5 $\mu \mathrm{M}$ ). To test its potential as a radiosensitizer, we assessed clonogenic survival after 4 Gy of the same eight GBM cell lines after a 1-hour treatment with MP470 followed by a single radiation dose (Fig. 1). Various levels of response were seen in the different cell lines, with 3 of the $8 \mathrm{GBM}$

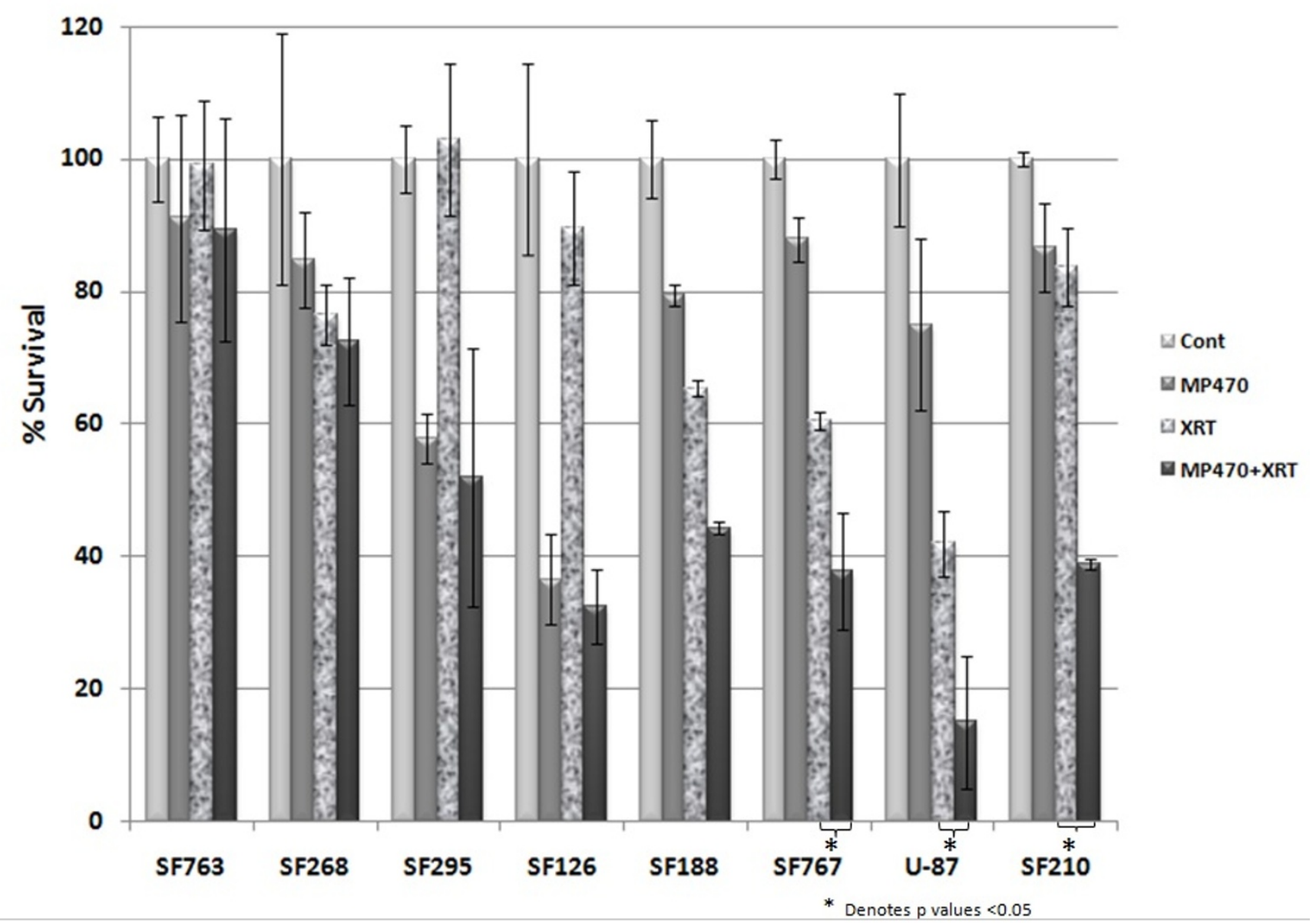

Figure I

Effect of MP470 and radiation on clonogenic survival of eight GBM cell lines. The combination of MP470 (5 $\mu$ M) plus radiation $(4 \mathrm{~Gy})$ produced the most cell killing of any treatment condition, but the extent of the responses varied among the different cell lines. The radiosensitizing effect of MP470 was most effective in the SF767, U87, and SF2 I 0 cell lines. Each bar is the mean of 3 experiments and error bars indicate standard deviation. 
lines appearing to have a greater then additive response when MP470 was combined with XRT. SF767 cells were chosen to assesses for clonogenic survival in response to increasing doses of radiation ( 0 to $8 \mathrm{~Gy}$ ) and MP470 had a radiosensitizing effect at all radiation doses tested, MP470 increased cell kill by $0.5 \log$ compared to 4 Gy alone (Fig. 2).

\section{MP470 inhibits GSK3 $\beta$ and induces apoptosis}

Having established the ability of MP470 to sensitize GBM cells to radiation, we next wanted to validate that it was acting through c-Met. SF767 cells demonstrate the presence of pMet and treatment with MP470 reduced c-Met phosphorylation (Fig. 3A), as assessed by immunoblotting analysis. In order to confirm MP470's mechanism of action we evaluated a known downstream pathway of cMet, phosphatidylinositol 3-kinase/Akt, in SF767 cells [15]. A 1-hour incubation with MP470 led to a reduction in pAkt protein in SF767 cells (Fig. 3B). To determine the effect of this reduction in pAkt on cell survival, we evaluated apoptosis and necrosis induced by radiation ( $8 \mathrm{~Gy}$ ), alone or after a 1-hour pretreatment with MP470, using an acridine orange assay. MP470 alone had no effect on cell death, and radiation alone induced a mild increase in cell death (this stands in contrast to the percent of death seen in a clonogenic assay, since the majority of radiation induced cell death is from mitotic division and not apoptotic). The combination of MP470 followed by radiation (8 Gy), however, killed 75\% of the cells (Fig. 4A). We next postulated that GSK3 $\beta$, a key regulator of the extrinsic

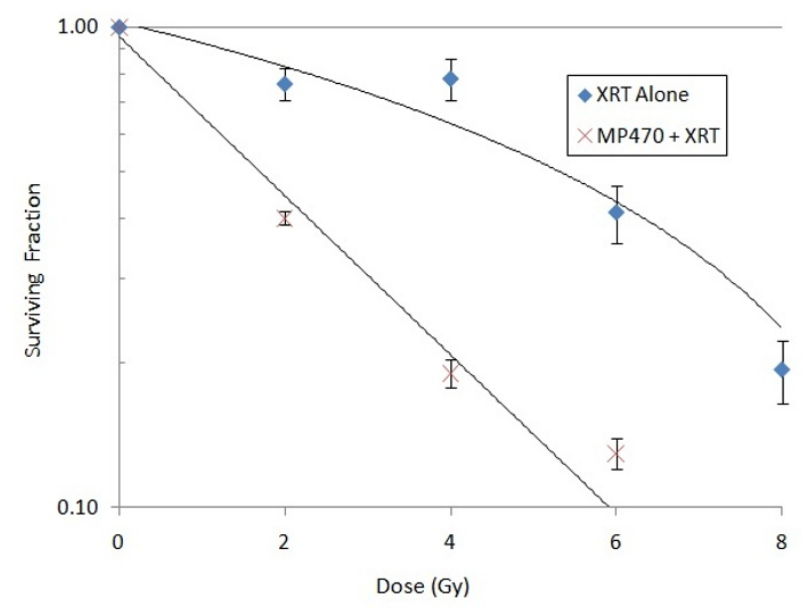

Figure 2

Clonogenic survival of SF767 cells treated with MP470 followed by irradiation in a range of radiation doses. Radiation at all doses had a moderate suppressive effect on clonogenic survival, and that effect was enhanced by pretreatment with MP470. Each data point represents the mean of 3 experiments \pm SD. apoptotic pathway [16], could play a role in this induction of apoptosis, as it is strongly regulated by Akt. We found that pretreatment with MP470 resulted in increased phosphorylation of GSK3 $\beta$ at serine-9 (Fig. 4B), a site known to inhibit GSK3 $\beta$ [16].

\section{Influence of MP470 on repair of dsDNA breaks}

To test the hypothesis that MP470 enhances radiationinduced cell death by influencing the repair of dsDNA breaks, we measured levels of $\gamma$-H2AX. At 1 hour after irradiation, both the control cells and the MP470-treated cells showed comparable numbers of $\gamma$-H2AX foci, suggesting that MP470 does not enhance the initial level of radiation induced dsDNA breaks. In order to detect an influence of MP470 on repair, we quantified the level of $\gamma$-H2AX foci several hours after irradiation. At 8 hours after irradiation, cells treated with XRT had a median densitometry intensity of 71 compared to 127 for cells treated with MP470 and XRT $\mathrm{p}=0.04$. (Fig. 5). To further evaluate MP470's affect on dsDNA repair, we supplemented our $\gamma$-H2AX results with a comet assay. At 1 hour after irradiation, SF767 cells treated with either radiation alone ( $8 \mathrm{~Gy}$ ) or with $10 \mu \mathrm{M}$ MP470 followed by irradiation showed similar levels of DNA damage, higher doses of MP470 and radiation were used here due to the low sensitivity of the comet assay. However, at 8 hours after irradiation, dsDNA repair was greatly inhibited in the cells that had been pretreated with MP470 $22 \pm 3.1$ tail DNA (\%), for 8-Gy irradiation alone and $35 \pm 4.3$ tail DNA (\%), for MP470 followed by 8-Gy irradiation). This increase in OTM suggests that MP470's radiosensitizing effect may be partially mediated through inhibition of dsDNA repair. RAD51 is a key regulator of homologous recombinational repair $[17,18]$ and our prior work has demonstrated that RAD51 level at the time of surgical resection is an independent prognosticator of survival in GBM patients [19], thus we evaluated whether MP470 could affect RAD51. RAD51 expression was noted to be increased ( $24 \mathrm{hrs}$ ) after the cells were irradiated. Pretreatment with MP470 decreased RAD51 expression in nonirradiated cells and suppressed the increase in expression prompted by radiation (Fig. 6A). This effect was dose-dependent, with the strongest suppression at MP470 concentrations exceeding $5 \mu \mathrm{M}$. To verify that MP470 was indeed decreasing RAD51 expression and not simply shifting cells into a quiescent cell cycle state $\left(G_{0}\right)$ characterized by lower levels of RAD51, we tested the effect of MP470 on cell cycle distribution and found it had no influence. To establish that RAD51 suppression was directly associated with c-Met inhibition, we silenced c-Met expression using siRNA, which also demonstrated inhibition of RAD51 (Fig. 6B).

\section{In vivo radiosensitization studies}

To validate the in vitro results, we implanted GBM cells subcutaneously in the flanks of nude mice and treated 


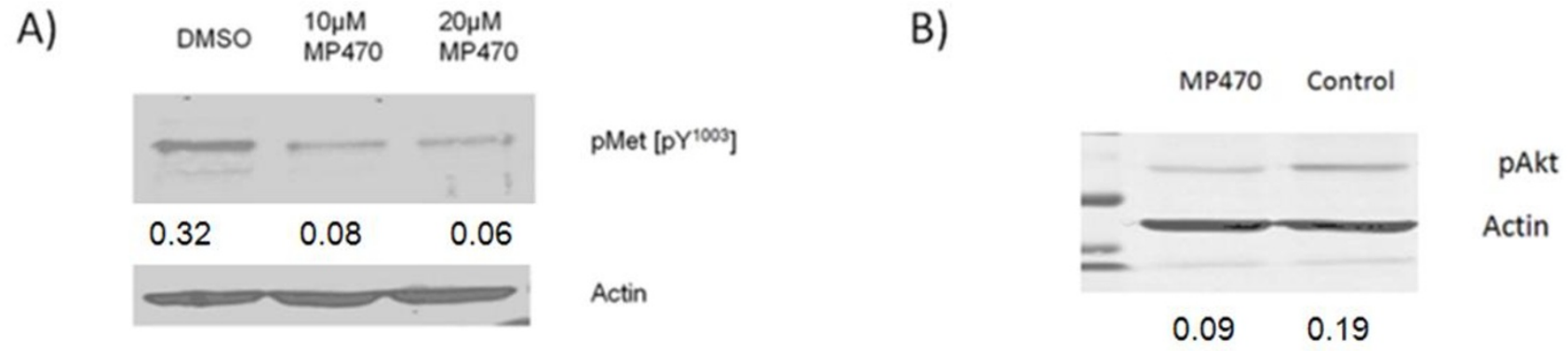

\section{Figure 3}

Western blot analysis of SF767 cell lines in response to MP470. (A) Treating SF767 cells with MP470 (I0 $\mu$ M) for I hr followed by stimulation with pervanadate led to reduced phosphorylation of c-Met [PY1003] in a dose-dependent manner, compared to DMSO control. (B) SF767 cells treated with MP470 (I0 $\mu \mathrm{M})$ for I hr showed reduced expression of pAkt protein.

those mice with MP470, irradiation, or both, with 8 animals per group. Treatment started on day 25 with MP470 which was given daily for 14 consecutive days, XRT was started on day 27 using a total of 20 Gy in 10 daily fractions, to the tumor alone. On day 48 after implantation the experiment was terminated and the tumors were measured. As shown in Fig. 7A, MP470 increased the AGD from $6.1 \pm 2.3$ days with radiation alone to $17.7 \pm 2.8$ days with the combination, resulting in an enhancement ratio of 2.9 (Table 1). Survival rates were evaluated on the final day of the experiment. At that time, survival rates were $0 \%$ in the vehicle-control or MP470-only groups, $50 \%$ in the radiation-only group $(P=0.035)$, and $87.5 \%$ in the MP470-plus-radiation group $(P=0.001)$ (Fig. 7B).

\section{Discussion}

The small molecule MP470 is a potent c-Met antagonist that is cytotoxic to a variety of cell lines in vitro [11]. In this report, we demonstrated that concurrent inhibition of cMet in combination with irradiation led to both reduced
A)

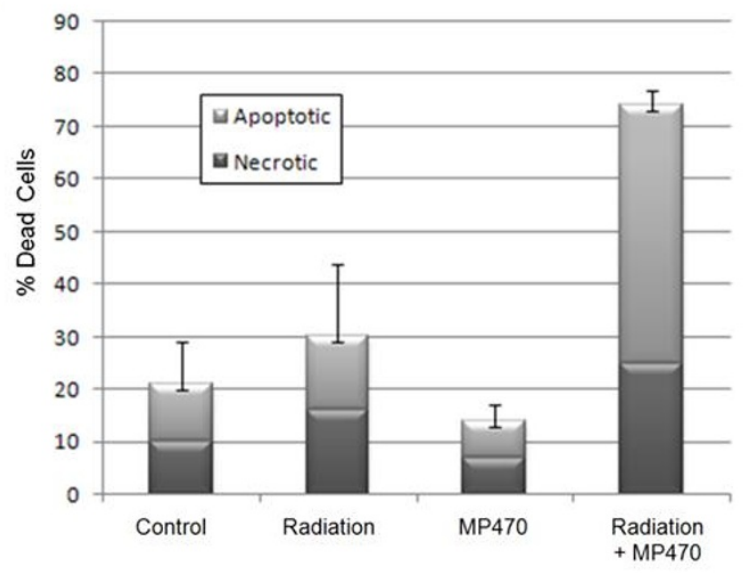

B)

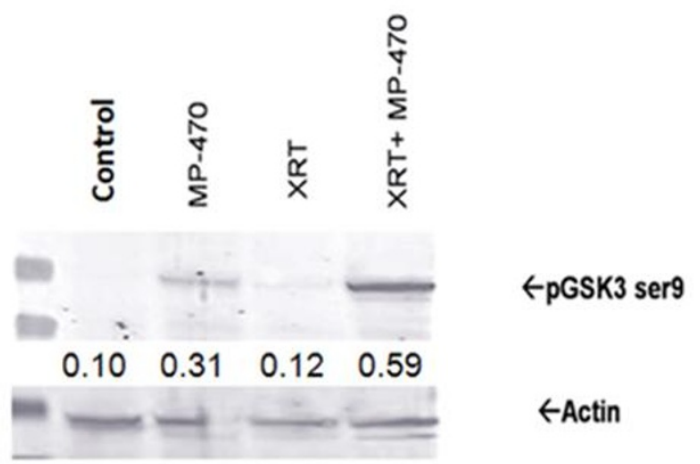

\section{Figure 4}

(A) Apoptosis and necrosis, quantified using an acridine orange assay, in SF767 cells after treatment with radiation, MP470, or both. MP470 (5 $\mu \mathrm{M})$ alone had no effect on the proportion of dead cells. Radiation (8 Gy) by itself induced some necrotic cell death but little apoptosis. However, the combination of MP470 followed by radiation greatly increased the proportions of both necrotic and apoptotic cells. Performed in triplicate: bars indicate mean \pm SD. (B) Western blot analysis of SF767 cells treated with radiation $(4 \mathrm{~Gy})$ alone had no influence on the expression of glycogen synthase kinase (GSK) $3 \beta$ phosphorylated at serine 9; however, treatment with MP470 (I0 $\mu \mathrm{M})$ or MP470 for 24 hrs followed by radiation enhanced the expression of this phosphorylated protein. 


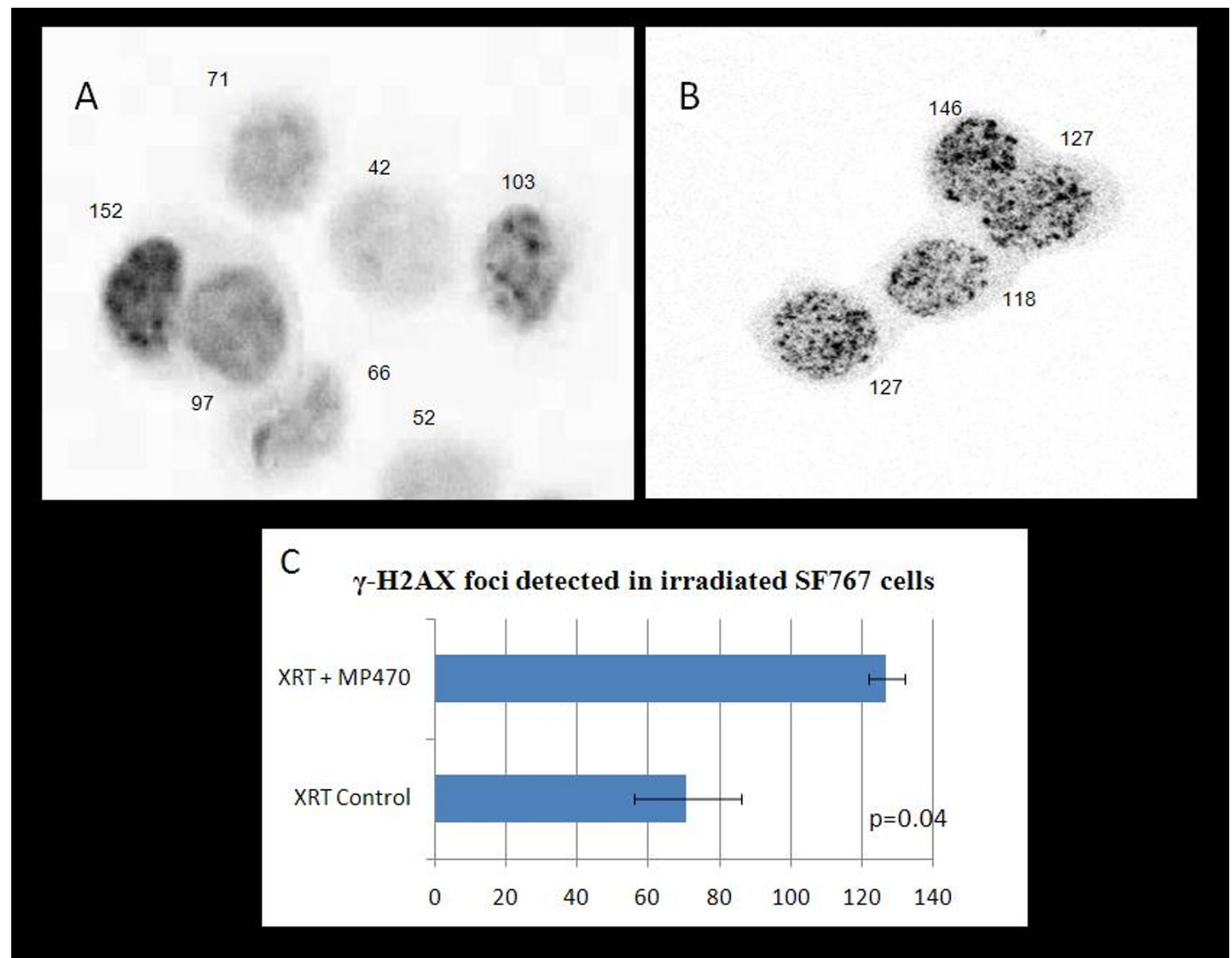

Figure 5

Photomicrographs of $\gamma-\mathrm{H} 2 \mathrm{AX}$ foci detected in irradiated SF767 cells. Cells were irradiated with 4 Gy, fixed 8 hours later, and then stained with anti- $\gamma-\mathrm{H} 2 \mathrm{AX}$ antibodies. Original magnification $\times 1,000$ (values indicate mean intensity, based on densitometry). (A) $\gamma-\mathrm{H} 2 \mathrm{AX}$ foci in SF767 cells treated with radiation alone. (B) Pretreatment with $5 \mu \mathrm{M}$ MP470, before radiation lead to increased $\gamma-\mathrm{H} 2 \mathrm{AX}$ foci. (C) Radiation plus MP470 resulted in a median $\gamma-\mathrm{H} 2 \mathrm{AX}$ foci intensity of 127 compared to 7I for radiation alone $\mathrm{p}=0.04$.

dsDNA repair and enhanced apoptosis in GBM. Our in vitro findings were supported by our in vivo observations using a xenograft model in nude mice. In this model, MP470 by itself, at a dose of $60 \mathrm{mg} / \mathrm{kg}$, had no effect on tumor size or survival; radiation by itself was somewhat more effective in reducing tumor volume and improving survival; but the combination of radiation plus MP470 produced the best response in terms of both local control and survival.

High-grade glial neoplasms of the brain continue to be one of the most challenging malignancies to treat, and their poor prognosis has improved only marginally over the past four decades (survival rates of $10 \%-20 \%$ at 2 years) [20]. Postoperative radiation provides a clear survival advantage for patients with gliomas, yet the majority of disease recurrences present within $2 \mathrm{~cm}$ of the postoperative bed-the very place targeted by the radiation. Unfortunately, attempts to escalate treatment doses to the tumor bed have provided only modest benefit [21]. To better understand why requires evaluating the cellular and molecular interactions in the resistant tumor cells. The pathway to malignancy consists of multiple genetic mutations, often in key regulators of the cell cycle or DNA repair process. These alterations allow cancer cells to not only divide unchecked, but also to repair DNA damage at 


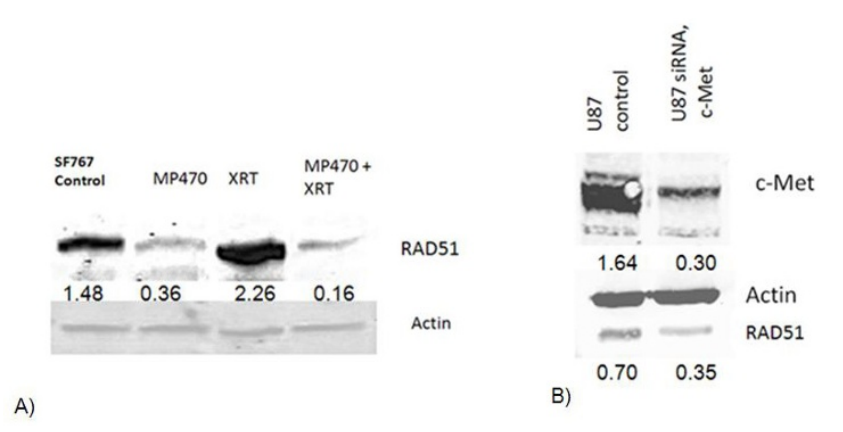

Figure 6

(A) Western blot analysis of SF767 cells showed constitutive expression of the RAD5 I which is elevated further after irradiation. MP470 (10 $\mu \mathrm{M})$ inhibited both constitutive and radiation-induced expression of RAD5 I protein. (B) Cells treated with siRNA to c-Met for 48 hours led to suppression of c-Met and reduced expression of RAD5I.

an accelerated or more efficient rate. One of the genes implicated in homologous recombination repair of dsDNA damage is RAD51. Prior work from our lab has demonstrated that RAD51 expression levels at the time of initial surgical resection are an independent prognosticator of survival for GBM patients receiving radiation [19]. In the present paper, we evaluated whether MP470 could influence RAD51 expression in GBM tumors cell and found that pretreatment with MP470 inhibited XRT induced expression of RAD51. This compliments our prior GBM tissue microarray findings that $70 \%$ of recurrent GBM tumors, treated with XRT, were found to have elevated RAD51 at the time of recurrence [19]. Paradoxically, this suggests that the ability of malignant cells to repair dsDNA damage can be enhanced by the very agents used to treat malignancies. The stimulation of RAD51 by radiation may explain why current therapies temporarily improve local control but fail to offer definitive cures. Clearly, substantial improvements in local control and survival of patients with GBM will require targeting (inhibiting) the molecular machinery that mediates the development of resistance.

To our knowledge, this is the first demonstration that $\mathrm{MP} 470$, an orally available c-Met antagonist, causes radiosensitization of several GBM cell lines. We have shown evidence that supports a mechanism of action consistent with a decrease in dsDNA break repair, along with enhanced radiation-induced apoptosis. Other investigators have shown that c-Met inhibition can enhance radiation-induced tumor cell death in vitro using a retrovirally based approach that would not be a clinically viable option, although it did serve as an important proof of concept [10]. This stands in contrast to MP470, which is well tolerated in animals, with no observable adverse effects from daily administration of $2,000 \mathrm{mg} / \mathrm{kg}$ to rats
A)

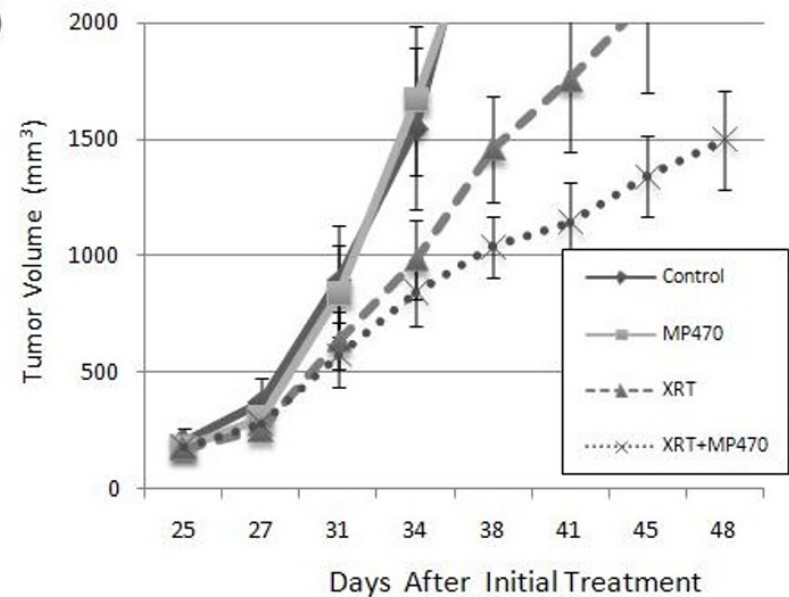

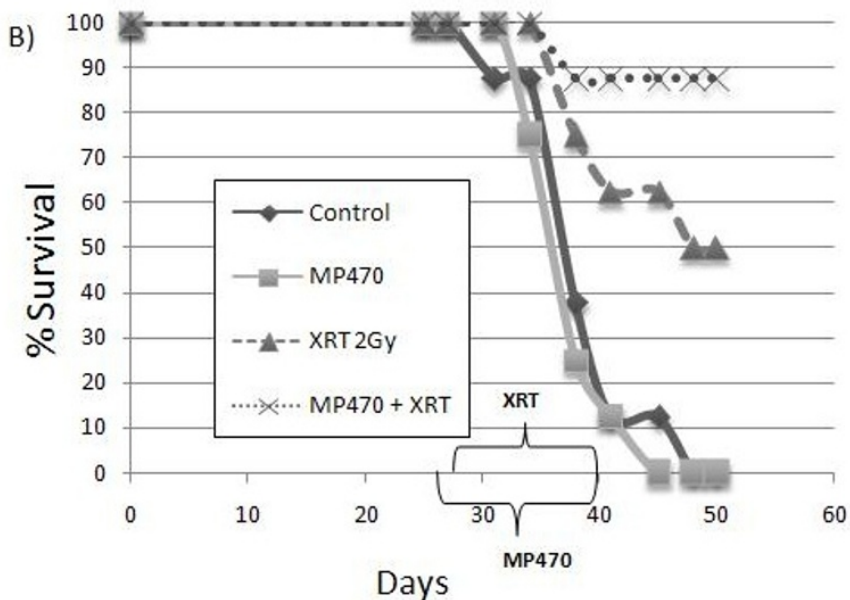

\section{Figure 7}

Tumor volume and survival in mice with subcutaneous U87 MG xenografts treated with MP470 and radiation. Tumor volume of $1,500 \mathrm{~mm}^{3}$ was used as a baseline for calculating tumor growth delays, and mice were euthanized once they reached $2000 \mathrm{~mm}^{3}$. (A) Irradiation alone resulted in a modest AGD of $6.1 \pm 2.3$ days, while the combination of MP470 plus irradiation produced an AGD of $17.7 \pm 2.8$ days, resulting in an enhancement ratio of 2.9 (Table I). (B) Kaplan-Meier survival rates on day 48 (the final day of the experiment) were $0 \%$ in both the control and MP470-alone groups, $50 \%$ in the radiationonly group $(P=0.035)$, and $87.5 \%$ in the MP470 + radiation group $(P=0.00 \mathrm{I})$. Each data point represents the mean of 8 tumors; bars indicate standard error. 
Table I: MP470-induced tumor growth delay in U87 xenografts

\begin{tabular}{|c|c|c|c|c|c|}
\hline Treatment Group & $\begin{array}{l}\text { No. of Mice Per } \\
\text { Group }\end{array}$ & $\begin{array}{l}\text { Tumor Growth } \\
\text { Period, days* }\end{array}$ & $\begin{array}{c}\text { Absolute Growth } \\
\text { Delay }{ }^{\dagger}\end{array}$ & $\begin{array}{c}\text { Normalized } \\
\text { Growth Delay } \ddagger\end{array}$ & $\begin{array}{l}\text { Enhancement } \\
\text { Factor** }\end{array}$ \\
\hline Control & 8 & $9.7 \pm 1.01$ & & & \\
\hline MP470 & 8 & $8.6 \pm 1.1$ & $0 \pm 1.1$ & & \\
\hline Radiation & 8 & $15.8 \pm 2.3$ & $6.1 \pm 2.3$ & & \\
\hline MP470 + Radiation & 8 & $27.4 \pm 2.8$ & $17.7 \pm 2.8$ & $17.7 \pm 2.8$ & 2.9 \\
\hline
\end{tabular}

* Time for subcutaneous tumors to grow from $200 \mathrm{~mm}^{3}$ to $1500 \mathrm{~mm}^{3}$ (see text).

† No. of days for tumors in the radiation-only and the MP470 + radiation groups to reach $1,500 \mathrm{~mm}^{3}$ minus no. of days for tumors in the control group to reach the same size.

$\ddagger$ No. of days for tumors in the MP470 + radiation group to reach $1,500 \mathrm{~mm}^{3}$ minus no. of days for tumors in the MP470-only group to reach the same size.

** Normalized growth delay for MP470 + radiation group divided by absolute growth delay for the radiation-only group.

and $240 \mathrm{mg} / \mathrm{kg}$ to dogs [22]. This initial work on MP470 provided the foundation to support a phase I trial, to establish the maximum tolerated dose of MP470 in humans. Our work reported here suggests that c-Met inhibition can offer therapeutically relevant radiosensitization and potentially improve the therapeutic ratio in radiationresistant tumors such as GBM.

\section{Competing interests}

James Welsh, Research support from SuperGen, holds patent on MP-470

Daruka Mahadevan, Co-discovered of MP470, holds patent on MP-470

David Bearss, Co-discovered of MP-470 and employee of Surgen, holds patent on MP-470

All other authors have no conflicts of interest.

\section{Authors' contributions}

JW developed the ideas for these experiments, performed much of the work, and drafted the manuscript. DM was involved with experimental design and provided resource to perform this work. RE performed some of the experiments. LC provided technical laboratory support. DB provided resource and technical advice. BS provided resources and participated in the design and coordination. All authors read and approved the final manuscript.

\section{Acknowledgements}

This work was supported by a grant from SuperGen and we would like to thank their support of our work. We thank the members of the Experimental Mouse Shared Services at the Arizona Cancer Center, along with the University of California San Francisco's generosity in sharing their GBM cell lines and Dr. Raymond Meyn, (M.D. Anderson Cancer Center) for his assistance in publication preparation.

\section{References}

I. Walker MD, Green SB, Byar DP, Alexander E, Batzdorf U, Brooks WH, Hunt WE, MacCarty CS, Mahaley MS, Mealey J, et al.: Randomized comparisons of radiotherapy and nitrosoureas for the treatment of malignant glioma after surgery: BTSG 7201. N England J Med 1980:1323-1327.

2. Lee SW, Fraass BA, Marsh LH, et al.: Patterns of failure following high-dose 3-D conformal radiotherapy for high-grade astrocytomas: a quantitative dosimetric study. Int $J$ Radiat Oncol Biol Phys 1999, 43:79-88.

3. Green S, Shapiro W, Burger P, Selker R, Van Gilder J, Saris S: A randomized trial of interstitial radiotherapy (RT) boost for newly diagnosed malignant glioma: Brain Tumor Cooperative Group (BTCG) trial 870I. Proc Ann Meet Am Soc Clin Oncol 1994, 13:174.

4. Fan S, Ma YX, Gao M, Yuan R-Q, Meng Q, Goldberg ID, Rosen EM: The multisubstrate adapter gabl regulates hepatocyte growth factor (scatter factor)-c-met signaling for cell survival and DNA repair. Mol Cell Biol 200I, $21: 4968-4984$.

5. Fan S, Ma YX, Wang J-A, Yuan R-Q, Meng Q, Laterra JJ, Goldberg ID, Rosen EM: The cytokine scatter factor inhibits apoptosis and enhances DNA repair by a common mechanism involving signaling through phosphatidylinositol 3' kinase. Oncogene 2000, 19:2212-2223.

6. Danilkovitch-Miagkova A, Zbar B: Dysregulation of Met receptor tyrosine kinase activity in invasive tumors. J Clin Invest 2002, 109:863-867.

7. Birchmeier C, Birchmeier W, Gherardi E, Vande GFW: Met, metastasis, motility and more. Nat Rev Mol Cell Biol 2003, 4:915-925.

8. Maulik G, Shrikhande A, KijimaT Ma PC, MorrisonPT RS: Role of the hepatocyte growth factor receptor, c-Met, in oncogenesis and potential for therapeutic inhibition. Cytokine Growth Factor Rev 2002, 13:41-59.

9. Toschi L, Janne PA: Single-Agent and Combination Therapeutic Strategies to Inhibit Hepatocyte Growth Factor/MET Signaling in Cancer. Clin Cancer Res 2008, I 4:594I-5946.

10. Lal B, Xia S, Abounader R, Laterra J: Targeting the c-Met Pathway Potentiates Glioblastoma Responses to $\gamma$-Radiation. Clin Cancer Res 2005, I I:4479.

II. Mahadevan D, Cooke L, Riley C, Swart R, Simons B, Della Croce K, Wisner L, lorio M, Shakalya K, Garewal H, et al.: A novel tyrosine kinase switch is a mechanism of imatinib resistance in gastrointestinal stromal tumors. Oncogene 2007, 26:3909-3919.

12. Parsa AT, Waldron JS, Panner A, Crane CA, Parney IF, Barry JJ, Cachola KE, Murray JC, Tihan T, Jensen MC, et al.: Loss of tumor suppressor PTEN function increases B7-HI expression and immunoresistance in glioma. Nat Med 2007, 13:84-88.

13. Collins AR: The comet assay for DNA damage and repair: principles, applications, and limitations. Mol Biotechnol 2004, 26:249-261.

14. Secrist JP, Burns LA, Karnitz L, Koretzky GA, Abraham RT: Stimulatory effects of the protein tyrosine phosphatase inhibitor, pervanadate, on T-cell activation events. J Biol Chem 1993, 268:5886-5893. 
15. Graziani A, Gramaglia D, Cantley LC, Comoglio PM: The tyrosinephosphorylated hepatocyte growth factor/scatter factor receptor associates with phosphatidylinositol 3-kinase. J Biol Chem 199I, 266:22087-22090.

16. Beurel E, Jope RS: The paradoxical pro- and anti-apoptotic actions of GSK3 in the intrinsic and extrinsic apoptosis signaling pathways. Progress in Neurobiology 2006:173-189.

17. Tarsounas M, Davies AA, West SC: RAD5 I localization and activation following DNA damage. Philos Trans $R$ Soc Lond B Biol Sci 2004, 359:87-93.

18. Kawabata M, Kawabata T, Nishibori M: Role of recA/RAD5 I family proteins in mammals. Acta Med Okayama 2005, 59:I-9.

19. Kumar R, Welsh J, Nagle RB, Green S, Stea B: Association between Rad-5 I Levels and Survival in Patients With Glioblastoma Multiforme Treated With Radiation Therapy. International Journal of Radiation Oncology*Biology*Physics 2007, 69:S63-S64.

20. Curran WJ Jr, Scott CB, Horton J, Nelson JS, Weinstein AS, Fischbach AJ, Chang CH, Rotman M, Asbell SO, Krisch RE, Nelson DF: Recursive Partitioning Analysis of Prognostic Factors in Three Radiation Therapy Oncology Group Malignant Glioma Trials. J Natl Cancer Inst 1993, 85:704-7I0.

21. Welsh JW, Sanan A, Gabayan AJ, Green SB, Lustig R, Burri S, Kwong E, Stea B: GliaSite Brachytherapy Boost as Part of Initial Treatment of Glioblastoma Multiforme: A Retrospective Multi-Institutional Pilot Study. International Journal of Radiation Oncology*Biology*Physics 2007, 68:159-165.

22. Joshi R, Kanekal S, Inloes R, Grand CL, Liu X, Vankayalapati H, Bernard L, Jones R, Bearss DJ, Redkar S: MP470.HCI, a Potent Suppressor of Rad5 I, Improves Bioavailability and Tolerability. AACR-NCI-EORTC 2007.

Publish with Bio Med Central and every scientist can read your work free of charge

"BioMed Central will be the most significant development for disseminating the results of biomedical research in our lifetime. "

Sir Paul Nurse, Cancer Research UK

Your research papers will be:

- available free of charge to the entire biomedical community

- peer reviewed and published immediately upon acceptance

- cited in PubMed and archived on PubMed Central

- yours - you keep the copyright

Submit your manuscript here:

http://www.biomedcentral.com/info/publishing_adv.asp
BioMedcentral 